\title{
High dose Chemotherapy and Stem Cell Support in a Patient of Light- and Heavy-chain Deposition Disease with Abnormal Marrow Cell Surface Antigens and No Monoclonal protein
}

\author{
Masanori SAKAKIMA, Yoshihide FUJIGAKI, Takayuki TsuJI, Hirotaka FuKASAWA, \\ Takehiko MiYAJI, Kensuke NAITO**, Tatsuo YAMAMOTO, Katsuhiko YonEMURA*, \\ Kazunori OHNISHI** and Akira HISHIDA
}

\begin{abstract}
A 53-year-old man with nephrotic syndrome and severe renal failure was diagnosed with light- and heavychain deposition disease (LHCDD) by renal biopsy. The patient had no monoclonal protein and mild marrow plasmacytosis $(6 \%)$, but marrow plasma cells expressed $\mathrm{CD}^{-} \mathrm{CD56}^{+}$and predominant monoclonal kappa-chain, indicating plasma cell dyscrasia. Conventional chemotherapy was ineffective and did not improve renal failure. High dose chemotherapy/peripheral blood stem cell transplantation (HDC/PBSCT) was introduced even after hemodialysis to eliminate aberrant clone and normalization of bone marrow cell surface markers. Immunophenotypic analysis of marrow cells facilitates clinical decision making regarding the use of HDC/PBSCT for LHCDD patients without monoclonal protein.

(Internal Medicine 44: 970-974, 2005)
\end{abstract}

Key words: hemodialysis, light- and heavy-chain deposition disease, marrow cell surface antigens, monoclonal protein, peripheral blood stem cell transplantation, renal failure

\section{Introduction}

Light- and heavy-chain deposition disease (LHCDD) was first reported in 1980 by Preud'homme et al (1), and is characterized by deposition of both monoclonal immunoglobulin light- and heavy- chains in several body organs. LHCDD belongs to the disease entity of monoclonal immunoglobulin deposition disease (MIDD) together with light-chain deposition disease and heavy-chain deposition disease (2), and an apparent clinical difference has not been reported among them. MIDD involves the kidneys most frequently, where patients present with proteinuria and renal insufficiency (2). Renal function deteriorates rapidly in most patients to endstage renal disease, and the reported patient survival is rather poor even in those who receive early and aggressive conventional chemotherapy (3). MIDD is often associated with multiple myeloma or monoclonal gammopathy of undetermined significance (MGUS), but about 20\% of MIDD have neither evidence of any overt plasma cell dyscrasia nor the presence of monoclonal protein in the serum or urine (4).

Here, we report a case of renal-biopsy proven LHCDD without monoclonal protein or marrow plasmacytosis (the criterion of malignant myeloma). Analysis of bone marrow cell surface markers suggested plasma cell dyscrasia. Accordingly, high-dose chemotherapy combined with peripheral blood stem cell transplantation (HDC/PBSCT) was considered appropriate. The treatment was successful in our patient who was placed on hemodialysis, resulting in normalization of marrow plasma cell surface markers.

For editorial comment, see p 915.

\section{Case Report}

A 53-year-old Japanese man had a history of proteinuria

From the First Department of Medicine, *Hemodialysis Unit, **the Third Department of Medicine, Hamamatsu University School of Medicine, Hamamatsu

Received for publication October 8, 2004; Accepted for publication April 5, 2005

Reprint requests should be addressed to Dr. Yoshihide Fujigaki, the First Department of Medicine, Hamamatsu University School of Medicine, 1-20-1 Handayama, Hamamatsu 431-3192 

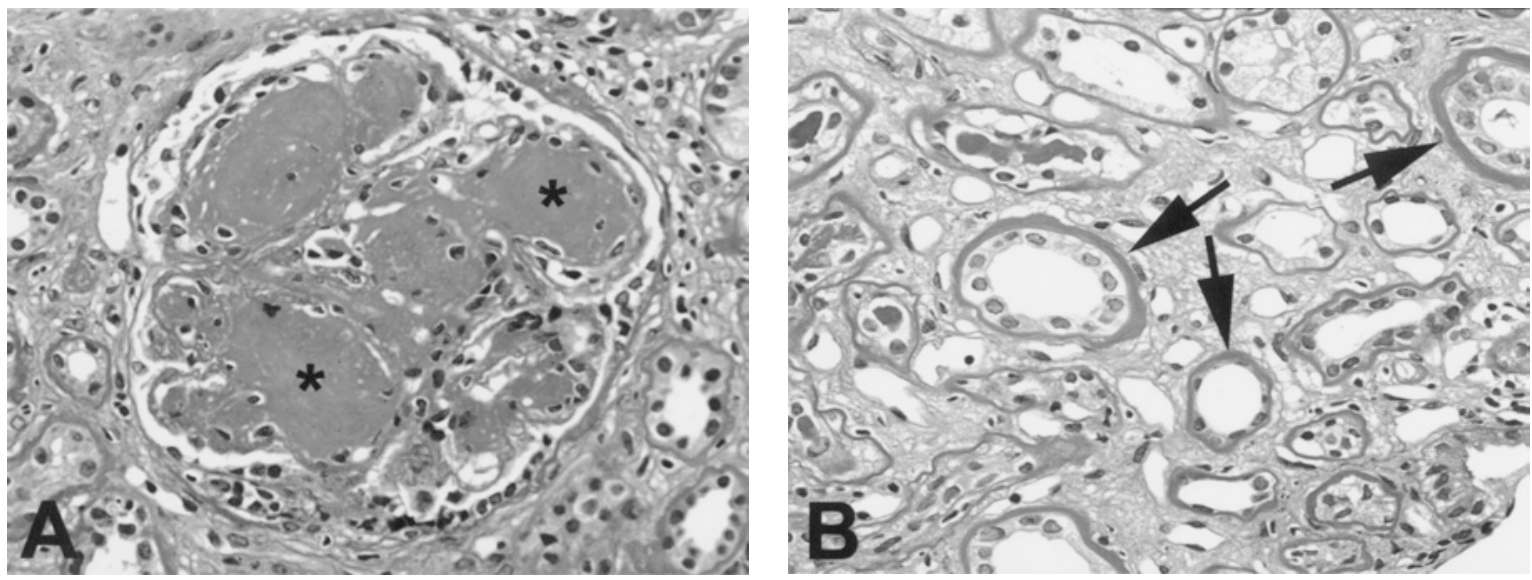

Figure 1. Light microscopic examination of renal tissue samples. (A) The glomerulus shows lobular formation and periodic acid-Schiff-positive mesangial nodular lesions (asterisks) with mild to moderate increase in mesangial cellularity at peripheral areas (periodic acid-Schiff stain, $\times 200$ ). (B) Atrophic tubules with thickening of the tubular basement membranes (arrows) (periodic acid-Schiff stain, $\times 400$ ).

identified on a routine medical examination at the age of 40 years, but no investigation of the cause was conducted. In February 2003, he noticed body weight gain $(10 \mathrm{~kg}$ over a 2 month period) and leg edema. On March 28, he was diagnosed as nephrotic syndrome with end-stage renal failure at a peripheral hospital and referred to our center for further investigation. On admission (May 26, 2003), physical examination revealed hypertension of $158 / 90 \mathrm{mmHg}$, pale conjunctiva, a grade 1/6 systolic murmur on chest auscultation and pitting edema in both legs. Laboratory tests showed a hemoglobin concentration of $8.3 \mathrm{~g} / \mathrm{dl}$, hematocrit of $23.5 \%$, reticulocytes $20 \%$, leukocyte count $10,200 / \mathrm{mm}^{3}$ and platelet count of $48.0 \times 10^{4} / \mathrm{mm}^{3}$. Blood chemistry was as follows: serum creatinine $3.2 \mathrm{mg} / \mathrm{dl}$, blood urea nitrogen $31.4 \mathrm{mg} / \mathrm{dl}$, total protein $4.3 \mathrm{~g} / \mathrm{dl}$, serum albumin $2.5 \mathrm{~g} / \mathrm{dl}$, total cholesterol $325 \mathrm{mg} / \mathrm{dl}$, triglyceride $574 \mathrm{mg} / \mathrm{dl}$, and cholinesterase $276 \mathrm{U} / \mathrm{l}$. Urinalysis revealed proteinuria of $7.2 \mathrm{~g} / \mathrm{day}$, slight hematuria but no glucosuria. The creatinine clearance was $38.5 / /$ day. Serological tests were normal or negative, including C-reactive protein, rheumatoid factor, hepatitis B surface antigen, hepatitis $\mathrm{C}$ virus antibody, complements 3 and 4, $50 \%$ hemolytic unit of complement, antinuclear antibody, anti-DNA antibody, and cryoglobulin. Immunoglobulin (Ig)G was $443 \mathrm{mg} / \mathrm{dl}$, IgA $94 \mathrm{mg} / \mathrm{dl}$, and IgM $118 \mathrm{mg} / \mathrm{dl}$. Serum and urine protein electrophoresis showed no monoclonal protein. An electrocardiogram showed left ventricular hypertrophy. Chest radiological examination showed mild pleural effusion without cardiomegaly or abnormal shadow in the lung fields. Abdominal echography showed swelling of both kidneys (right $13.4 \times 5.7 \mathrm{~cm}$, left $13.0 \times 5.2 \mathrm{~cm}$ ) and echocardiography revealed mild left ventricular hypertrophy without apparent sign of deposition.

A renal biopsy was performed on May 29, 2003 to evaluate the nephrotic syndrome. One glomerulus was detected with global sclerosis and one with fibrocellular crescent formation out of 39 glomeruli obtained. Most glomeruli showed lobular formation and periodic acid-Schiff (PAS)-positive but periodic acid-silver methenamine-negative mesangial nodular lesions with a mild to moderate increase in cellularity at peripheral areas (Fig. 1A). The glomerular capillary walls sometimes showed a partial double contour. Tubular atrophy with thickening of the tubular basement membrane and intimal thickening of small arteries were found (Fig. 1B). There was interstitial fibrosis associated with slight round cell infiltration in about $80 \%$ of tubulointerstitial areas (data not shown). Congo-red staining for amyloid was negative (data not shown). Immunofluorescent study was negative for $\operatorname{Ig} \mathrm{A}, \operatorname{IgM}, \mathrm{C} 3, \mathrm{C} 4$ and $\mathrm{C} 1 \mathrm{q}$. Mild to moderate staining for IgG was found in the mesangial nodular lesions and along the glomerular capillary walls, Bowman's capsules, the tubular basement membranes and small arteries (Fig. 2A). Identical staining patterns of kappa- and gammachains but not lambda-chain were found (Fig. 2B-D). Based on the above laboratory and histopathological findings, the patient was diagnosed as LHCDD. Electron microscopy showed fine granular electron dense deposits along the inner aspect of the glomerular basement membranes, and on the outer side of the tubular basement membranes and the subendothelium of the small arteries; but apparent deposits could not be found in the nodular lesions (Fig. 3A-C).

Biopsies of gastric mucosa and rectal mucosa showed no deposition of light- or heavy-chains. Bone marrow examination showed $6 \%$ of plasma cells without morphological abnormalities, but flow cytometric immunophenotypic analysis showed that these cells expressed CD19-CD56 ${ }^{+}$(Fig. 4A), which is compatible with the pattern of multiple myeloma that can be distinguished from the pattern of normal plasma cells $\left(\mathrm{CD} 19^{+} \mathrm{CD} 56^{-}\right)(5)$. Cytoplasmic light chain analysis of 

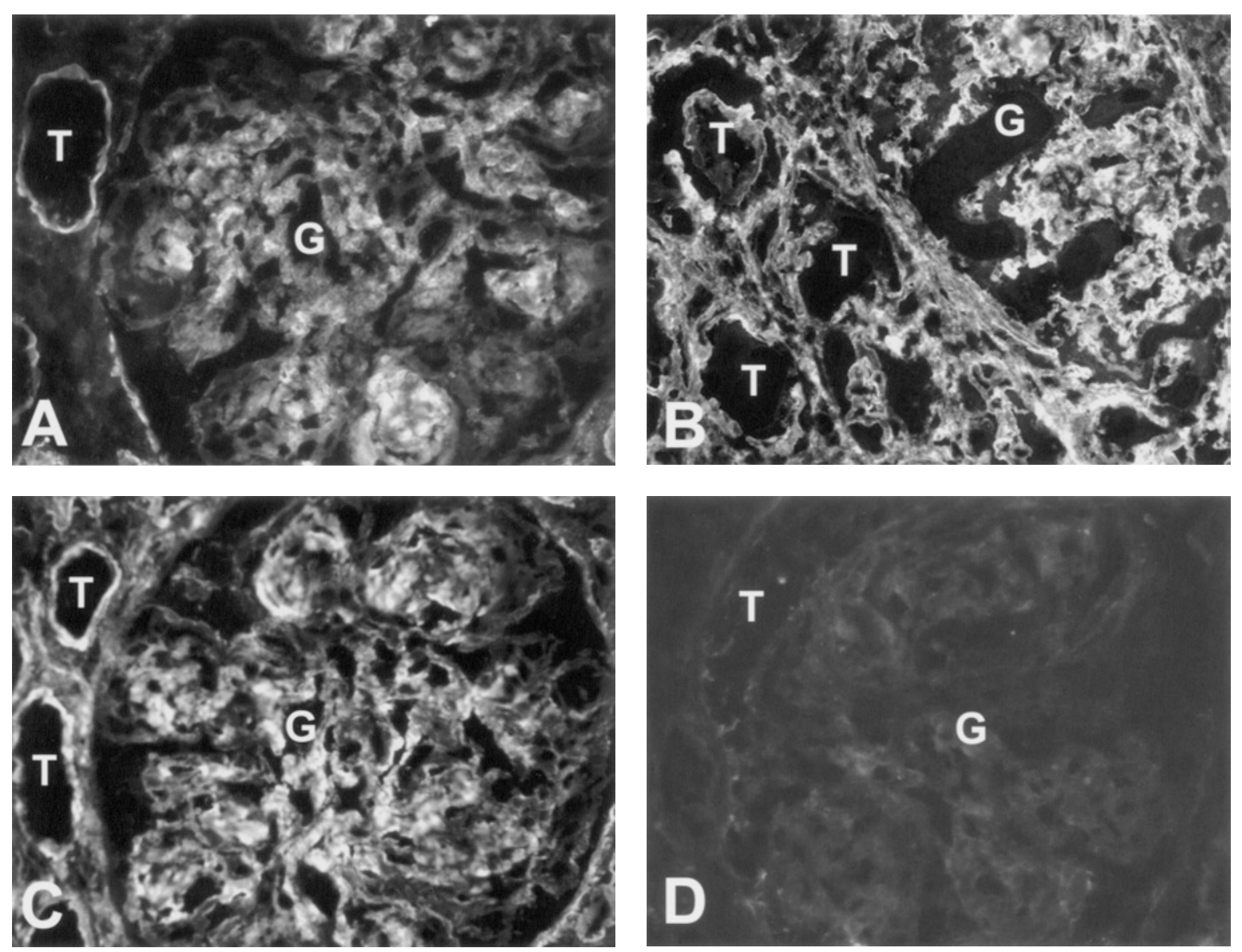

Figure 2. Immunofluorescent staining for immunoglobulin G (A), gamma-chain (B) and kappa-chain (C) in glomerular mesangial nodular lesions, glomerular capillary walls, Bowman's capsule and tubular basement membranes. Immunostaining for lambda chain (D) is negative. G: glomeruli, T: tubules $(A, C, D, \times 400 ; B, \times 300)$.

bone marrow plasma cells revealed that the $\kappa: \lambda$ ratio was 12.5 (Fig. 4B) [the criteria for light chain restriction in the normal population is as follows : monoclonal $\kappa, \kappa: \lambda$ ratio $\geqq 3$; monoclonal $\lambda, \kappa: \lambda$ ratio $\leqq 0.5$ (6)], indicating plasma cell dyscrasia.

To improve renal failure and prevent extrarenal deposition of light- and heavy-chains, we started vincristine-doxorubicin-dexamethasone therapy on July 22, 2003, and the course was repeated three times. However, this treatment produced no beneficial effects on renal function. Although hemodialysis commenced on November 10, 2003, HDC/PBSCT was introduced to eliminate the aberrant clone. The number of CD34+ cells obtained was $2.07 \times 10^{6} / \mathrm{kg}$ body weight. PBSCT was performed after melphalan $\left(140 \mathrm{mg} / \mathrm{m}^{2}\right)$ treatment. Granulocyte colony-stimulating factor (G-CSF) (300 $\mu \mathrm{g})$ (Kirin Brewery Co., Tokyo, Japan) was administered subcutaneously, daily from day 1 after PBSCT. On day 11 after PBSCT, the neutrophil count was $500 / \mathrm{mm}^{3}$, and on day 18 , the platelet count was $5.0 \times 10^{4} / \mathrm{mm}^{3}$ and reticulocytes $10 \%$. This was considered to represent sufficient bone marrow recovery and plasma cell markers after PBSCT showed nor- malization (Fig. 4C, D). Sixteen months after PBSCT, the patient remains on hemodialysis without any evidence of involvement of LHCDD in other body organs.

\section{Discussion}

Reports of LHCDD are rare, but it is considered that LHCDD is a variant of LCDD, showing similar clinicopathological pictures of LCDD (3). Renal dysfunction and proteinuria are the major laboratory and clinical findings at the onset of LHCDD like LCDD. A recent retrospective analysis of 5 patients with LHCDD (3) showed a mean serum creatinine of $5.3 \pm 2.0 \mathrm{mg} / \mathrm{dl}( \pm \mathrm{SEM})$ and proteinuria of $2.9 \pm 1.0 \mathrm{~g} /$ day at the time of renal biopsy, and one patient had multiple myeloma and 3 had MGUS. In other reports of patients with $\mathrm{L}(\mathrm{H}) \mathrm{CDD}$, about $20 \%$ showed no detectable monoclonal protein in the serum and urine by conventional analysis, similar to the present case (4). Considered together, these findings suggest that in most cases with no detectable monoclonal protein, abnormal immunoglobulin molecules are secreted and are either rapidly degraded post syntheti- 

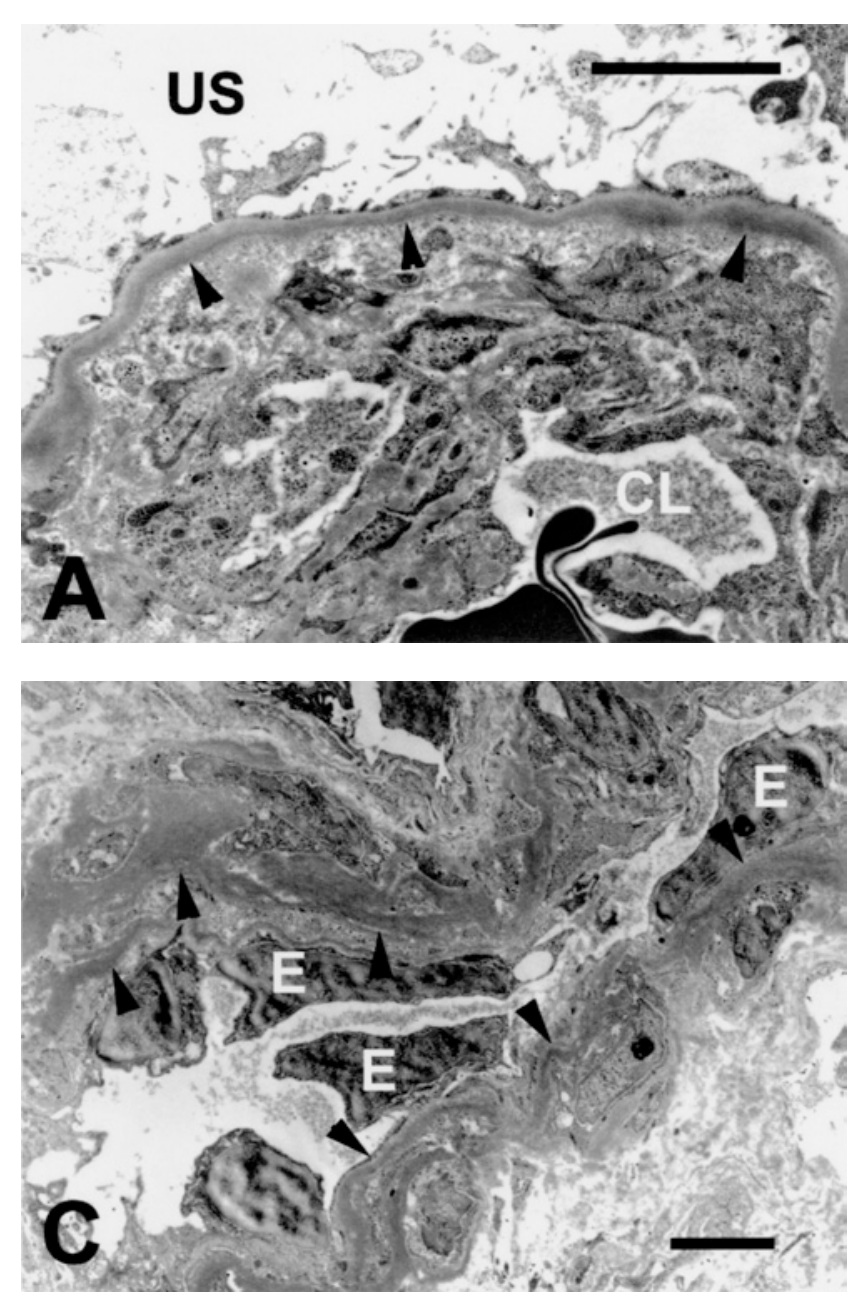

cally or deposited in tissues (2).

It is reported that renal and patient survivals were significantly worse in LCDD patients with coexistent myeloma cast nephropathy (mean, 4 and 22 months, respectively), compared with patients with pure MIDD (mean, 22 and 54 months, respectively) (3). However, renal and patient survivals were not influenced by the presence of multiple myeloma in 34 cases of MIDD without myeloma cast nephropathy (3). In another report, analysis of 63 cases of LCDD revealed that the median time from diagnosis to renal death was 2.7 years and the median survival was 4.1 years and that cases with multiple myeloma or with symptomatic extrarenal light chain depositions were associated with a worse outcome than those without (7). MIDD is considered as a systemic disease frequently involving the heart and liver except kidney (7), and cardiac failure or hepatic failure may cause patient death upon progression of the disease $(7,8)$.

Chemotherapy for multiple myeloma has been applied for cases of MIDD with definite multiple myeloma. However, there is no consensus regarding chemotherapy, with potential severe adverse effects, and whether it should be introduced in cases without definite malignant hematological diseases as in the present case. In recent years, the diagnosis of hemato-

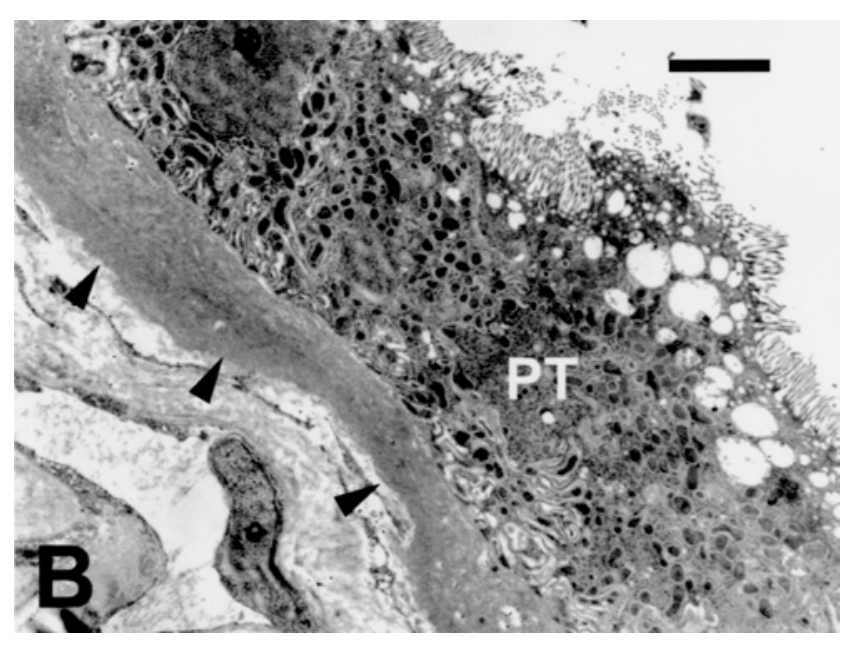

Figure 3. Electron microscopic examination showed the presence of fine granular electron-dense deposits (arrowheads) in the inner aspect of the glomerular basement membrane (A), in the outer aspect of the tubular basement membrane (B) and in the subendothelium of small arteries (C). CL: capillary lumen, US: urinary space, PT: proximal tubule, E: endothelial cells. Bars $=\mathbf{3 . 0} \mu \mathrm{m}$.

logical malignancy is based not only on morphology but also on immunophenotyping using cell surface markers (5), however, the clinical importance of abnormal cell surface markers without definite malignant hematological diseases has not been clarified. We made a decision to use vincristinedoxorubicin-dexamethasone-therapy in the present patient based on 1) bone marrow cell surface markers, which showed a pattern similar to that of multiple myeloma and plasma cell dyscrasia, 2) the patient was under 60 years of age and 3) the patient showed no evidence of other organ involvement apart from the kidney. In LCDD, it is reported that chemotherapy resulted in the reduction of proteinuria, improvement of renal function and disappearance of glomerular nodular lesions 7 months after the treatment (9), however, hemodialysis had to be introduced in the present case because of no apparent benefit of the therapy.

Autologous PBSCT is one of the therapeutic options in selected patients with multiple myeloma and ALamyloidosis even with renal involvement, and a favorable remission rate has been reported (10-12). To date, few patients with $\mathrm{L}(\mathrm{H}) \mathrm{CDD}$ have been treated with HDC/PBSCT. Recently, Royer et al treated 11 patients with L(H)CDD by $\mathrm{HDC} / \mathrm{PBSCT}$, who were under 65 years of age, including 4 

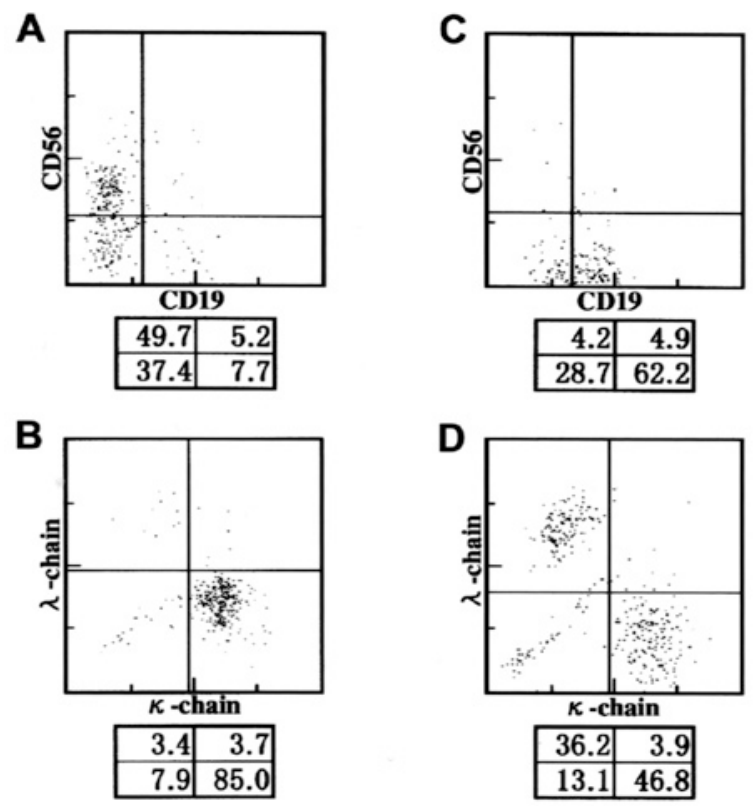

Figure 4. The surface expression of CD19 and CD56 (A, C), and intracellular expression of kappa and lambda chains $(B, D)$ in bone marrow plasma cells before $(A, B)$ and after HDC/PBSCT (C, D). Marrow plasma cells were identified using CD38 fluorescence and side-scatter gating, then unstimulated isolated marrow plasma cells were stained with both anti-CD19 and anti-CD56 monoclonal antibodies (A, C), and both antikappa chain and anti-lambda chain monoclonal antibodies (B, D), and analyzed using flow cytometry. The percentages of cells are shown in each of the quadrants.

dialysis cases. They reported that no toxic death occurred and the reduction of the monoclonal protein level in 8 cases with complete disappearance from serum and urine in 6 cases and improvement in organ dysfunction related to monoclonal immunoglobulin deposits in 6 cases (13). The present patient underwent hemodialysis 16 months after HDC/PBSCT, however, clones producing abnormal lightand heavy-chains had disappeared because of normalization of cell surface marker abnormalities (Fig. 4). It is necessary to follow-up the patient carefully by monitoring echocardiography and liver enzyme tests for cardiac and hepatic involvement with light- and heavy-chain depositions, since there is no specific serological markers.

Flow cytometric immunophenotypic analysis of bone marrow plasma cells may facilitate clinical decision making regarding the use of aggressive chemotherapy or HDC/ PBSCT in potentially poor survival patients of LHCDD without detectable monoclonal protein.

\section{References}

1) Preud'homme JL, Morel-Maroger L, Brouet JC, Mihaesco E, Mery JP, Seligmann M. Synthesis of abnormal heavy and light chains in multiple myeloma with visceral deposition of monoclonal immunoglobulin. Clin Exp Immunol 42: 545-553, 1980.

2) Preud'homme JL, Aucouturier P, Touchard G, et al. Monoclonal immunoglobulin deposition disease (Randall type). Relationship with structural abnormalities of immunoglobulin chains. Kidney Int 46: 965-972, 1994.

3) Lin J, Markowitz GS, Valeri AM, et al. Renal monoclonal immunoglobulin deposition disease: the disease spectrum. J Am Soc Nephrol 12: 1482-1492, 2001.

4) Buxbaum JN, Chuba JV, Hellman GC, Solomon A, Gallo GR. Monoclonal immunoglobulin deposition disease: light chain and light and heavy chain deposition diseases and their relation to light chain amyloidosis. Clinical features, immunopathology, and molecular analysis. Ann Intern Med 112: 455-464, 1990.

5) Harada H, Kawano MM, Huang N, et al. Phenotypic difference of normal plasma cells from mature myeloma cells. Blood 81: 2658-2663, 1993.

6) Witzig TE, Li CY, Tefferi A, Katzmann JA. Measurement of the intensity of cell surface antigen expression in B-cell chronic lymphocytic leukemia. Am J Clin Pathol 101: 312-317, 1994.

7) Pozzi C, D’Amico M, Fogazzi GB, et al. Light chain deposition disease with renal involvement: clinical characteristics and prognostic factors. Am J Kidney Dis 42: 1154-1163, 2003.

8) Ganeval D, Noel LH, Preud'homme JL, Droz D, Grunfeld JP. Lightchain deposition disease: Its relation with AL-type amyloidosis. Kidney Int 26: 1-9, 1984

9) Komatsuda A, Wakui H, Ohtani H, et al. Disappearance of nodular mesangial lesions in a patient with light chain nephropathy after longterm chemotherapy. Am J Kidney Dis 35: E9, 2000.

10) Child JA, Morgan GJ, Davies FE, et al. High-dose chemotherapy with hematopoietic stem-cell rescue for multiple myeloma. N Engl J Med 348: 1875-1883, 2003.

11) Skinner M, Sanchorawala V, Seldin DC, et al. High-dose melphalan and autologous stem-cell transplantation in patients with $\mathrm{AL}$ amyloidosis: An 8-year study. Ann Intern Med 140: 85-93, 2004.

12) Casserly LF, Fadia A, Sanchorawala V, et al. High-dose intravenous melphalan with autologous stem cell transplantation in AL amyloidosis-associated end-stage renal disease. Kidney Int 63: 1051-1057, 2003.

13) Royer B, Arnulf B, Martinez F, et al. High dose chemotherapy in light chain or light and heavy chain deposition disease. Kidney Int 65: 642648, 2004. 